\title{
Jordanian Society and the Tourism Profession from the Point of View of Tourism Workers
}

\author{
Mohammad Nayef Alsarayreh ${ }^{1}$ \\ ${ }^{1}$ Al-Balqa Applied University, Jordan \\ Correspondence: Mohammad Nayef Alsarayreh, Al-Balqa Applied University, Jordan. E-mail: \\ mohammad_n_k_s@yahoo.com
}

Received: October 10, 2018

Accepted: November 2, 2018

Online Published: November 10, 2018

doi:10.5539/ijbm.v13n12p1

URL: https://doi.org/10.5539/ijbm.v13n12p1

\begin{abstract}
Tourism has become one of the important industries of the world at present. The growth rates of agriculture and industry have exceeded the importance of all manufacturing and service industries in terms of sales, employment and foreign labor.

The study reached a number of results, the most important of which is that there is no statistically significant relationship between the Jordanian society's view of the tourism profession from the point of view of tourism workers and the social and personal fields.

The study recommended a number of recommendations, the most important of which is the need to improve the Jordanian society's view of the tourist profession by introducing Jordanian citizens to the importance of the tourism sector.
\end{abstract}

Keywords: Jordanian society, tourist, tourism workers, social sphere, personal domain

\section{Introduction}

Tourism in Jordan is one of the most important sectors in the country's economy. It accounts for $13 \%$ of the GDP. The tourism sector in Jordan witnessed rapid growth, accompanied by a significant increase in direct employment in the tourism sector. A growing sector.

The importance of tourism in the development of society has emerged in the first place in the expansion of the individual's perception of the importance of the environment surrounding it and its religious, historical or ecological sites, which are attractive attractions for tourists, and then we turn to the possibility of increasing its culture by studying these sites either during school classes or joining the tourist specialties in universities It is important to find a job in the field of tourism, especially if we know that the tourism sector is able to create many jobs. For example, the tourism industry in Jordan provides about 45 thousand jobs directly, not to mention indirect jobs, but tourism is characterized by continuous growth and Variety of jobs And is thus one of the most combative sectors that fight unemployment that threatens all societies in general.

Which prompted a number of universities and colleges to open specialties for tourism to the degree of diploma and bachelor. Where there are more than 20 universities, colleges and institutes in Jordan that offer different degrees in specializations and tourism.

But there are obstacles to work in the tourism sector that the culture of a defect and the view of society is the most important handicap facing the worker in the tourism sector, which is the main reason that reduces the chances of integration of the community in the tourism sector.

It is necessary to provide the appropriate awareness campaigns and the necessary funding to train the community and raise the competencies of the labor force to be an effective component in the actual production process. It is necessary to change the black outlook that is directed towards work in the tourism sector. The culture of a defect is the most important obstacles facing the work in the tourism sector.

\section{Literature Review}

Razan Falah Al-Zu'bi and others (2015), Youth attitudes towards women's work in the tourism sector: A study of the situation of students at the University of Jordan. 
The study aimed to identify the attitudes of young people towards the work of women in the tourism sector in Jordan by identifying the relationship between the social, demographic and economic variables and the desire of the youth in the work of women in the tourism sector and identifying the challenges that prevent the work of women in the tourism sector and their relation to the demographic, As well as to identify the aspirations and solutions that may contribute to increase the participation of women in the tourism sector from the perspective of young people. The study population consists of students of the University of Jordan in the faculties of Business Administration, Languages, History, Tourism, Archeology and Information Technology. The number of male and female students in these colleges reached 6548 students, A statistical tool was used to measure the attitudes of male and female students towards the work of women in the tourism sector. The Statistical Analysis Program (SPSS) was used to analyze data Descriptive statistical methods were used (ANOVA) to examine the differences between the averages of the different variables as well as the tests of the independent variables The study concluded that there is a positive trend among the students towards the exit of women to the labor market, The results showed that although there is a positive trend among both male and female students towards the work of women in the tourism sector to a medium degree, they still prefer the traditional professions more than the work in the sector tourism.

Khaled maqapleh et al. (2008), Local communities' awareness of the role of the Jordanian tourist guide in tourism development

The main objectives of the study were to identify the reality of the profession of tourism guidance in the Kingdom and its development over the past years, and to analyze the awareness of local communities, especially oriental boutiques towards the tourist guide. Within the framework of this survey, a questionnaire was prepared for this purpose, which included 37 words on the scale of the five-dimensional Likert to identify the local communities' awareness of various aspects related to the role of the Jordanian tourist guide in six tourist areas within the three tourist regions in the Kingdom. The study found that the local community believes that the tour guide is a model for the tourists accompanying them, and that it is his duty to take care to enhance the image of Jordan as a tourist destination. It was also revealed that the awareness of the local communities of the role of the tourist guide tends to negative evaluation with the concentration of shops aimed at serving tourists within restricted areas, in addition to the nature of the tourist trip in terms of limited visit to limited hours and the lack of tourism program and the weakness of trends in the region. This negative trend is also reinforced by the fact that the touristic trips are predominantly of a collective nature accompanied by a tour guide. The study also found that there are no statistically significant differences between the tourist areas with regard to their understanding of the role of the Jordanian tourist guide. The study recommended the need to overcome the gap in the perception among the local communities of the role of the tour guide, because of the potential negative effects on the overall tourism process. It is the role of the same guide to the need to improve the mental image in the eyes of local communities through positive behavior and construction and growing interest in community development and promotion The Association of Jordanian Tour Guides also plays an active role by promoting the profession of tourism guidance and preserving the rights and interests of members through specialized courses, workshops and periodic meetings with various tourist events. It is necessary to play an active role for the official authorities concerned with the process of tourism development in the field of licensing, monitoring and follow-up work of the tourist guide and update the laws and regulations governing the profession of tourism guidance in the Kingdom. The Association of Travel and Tourism Agents, the Association of Inbound Tourism and other interested parties can play an important role in revising tourist programs, in terms of including free time and necessary shopping hours in various tourist areas. Such practices can contribute to strengthening the relationship between the local community and tourists and improve the mental image and perception of the tourist guide.

Salwa al-Samarrai and others (2012), the availability of technical and scientific skills among the workers in the tourism sector, an applied study of a sample of workers in the tourism sector in the Hashemite Kingdom of Jordan.

In the last quarter of the twentieth century, Jordan was attracted to the tourism sector and attracting international tourism through the creation of the appropriate factors. Jordan enjoys the following advantages: The geographical location of the world's most prominent, where Jordan is the three continents of Asia and Jordan is one of the most stable countries in the region. The Middle East from France and Europe, economic and security aspects and all this encouraged tourism investment in it. Despite the great activity that is taking place in the tourism sector in Jordan, there is an important fact in this regard, namely that tourism in our time needs trained and qualified workers in terms of scientific and technical ability to cope with the development in the global tourism sector. As the tourism companies in the world are the use of computers and the Internet is an important 
means to introduce the activity of tourism offices and companies, in addition to the definition of tourist sites in their countries. As well as provide all the necessary information needed by the tourist when visiting or staying in their own countries. All this can only be achieved through a clear strategy for the development of human resources in the use of information technology in the tourism and hotel sector. So as to qualify and train young people who wish to work in this field in terms of scientific and technical in order to promote the tourism sector and hotel.

Asad Abu Rumman et al. (2013), Tourism Awareness and its Role in Enhancing the Competitiveness of Tourism and Travel Sector in Jordan: An Analytical Field Study.

This study deals with the level of tourism awareness in Jordanian society following the awareness building plan adopted by the Ministry of Tourism through reviewing the methods used to build awareness. The study focused on three strategies: tourism planning, tourism education and tourism marketing. The study was conducted on a wide sample of employees and those interested in tourism from teachers, principals, students, opinion leaders, and others. The study used many statistical methods, including regression analysis. The study found that the most The darling in the sector in the competitive field of human resources was the tourism planning and education tourism, while tourism education and tourism marketing, the most influential in the competitive sector in the field of awareness and understanding of national tourism, and finally marketing was only the most influential in the security and safety index.

Rafik Bouderbala (2016) Tourism awareness and its role in the development of the Algerian tourism sector

Tourism awareness is a key element that can not be overlooked when planning for the development and development of the tourism sector. Tourism awareness is of great importance in improving the tourism image in society and minimizing some of the negative effects that accompany the tourism industry in any country. And is aware of the importance of the achievements and successes achieved by the tourism sector and the sector offers opportunities and economic gains that are ultimately reflected on the members of the community. The aim of this paper is to shed light on the role of tourism awareness in achieving tourism development, improving the tourism image of Algeria and contributing to creating awareness to understand the tourism activity of the concerned authorities in re-planning tourist areas and interest in promising areas that have a tourist environment capable of attracting international tourism.

\subsection{The Importance of the Study}

The importance of the study is to try to draw attention to the role of the tourism sector as a supporter of the economy, which will contribute to increasing national income and providing important revenues in foreign currency, and highlights the importance of the community's view of tourism and work in the tourism profession in order to achieve comprehensive tourism development.

Tourism has become one of the important industries of the world at present. The growth rates of agriculture and industry have exceeded the importance of all manufacturing and service industries in terms of sales, employment and Jordanian society.

\subsection{The Objective of the Study}

This study aims:

1. Analysis of the demographic factors of a sample of Jordanian society towards the profession of tourism

2. Identifying the actual mental image of Jordanian society towards the profession of tourism

3. Knowledge of the sense of the employee working in the tourism sector and the view of the community as a staff member in the tourism sector.

The study Problem:

The problem of this study is the importance of the tourism sector for the Jordanian economy and the industry's contribution to GDP and thus the impact on the national income of the country. These strategies emerged from the Jordanian vision that the tourism sector in Jordan is growing rapidly and will contribute to improving the situation. The economic objectives of the Jordanians have been one of the most important strategic goals to increase tourism revenues, and work on the development of the labor market through increasing hands currency in the tourism sector

The tourism sector should have a clear priority as an alternative to sustainable economic growth in the event of a definite and expected depletion of oil, especially since Jordan has the potential of tourism such as beaches, forests, mineral baths, material and intangible cultural heritage. For the tourism profession. 


\section{Type of Study and Methodology}

This study belongs to the analytical exploratory studies and adopts the method of data collection and analysis to reach the results. The study is conducted on the employees of tourism in Jordan, 300 questionnaires were distributed, 270 of which were returned and 20 were excluded. We relied on (250) questionnaires that we were able to obtain and collected data from them through the questionnaire, representing the research community and the sample of the study.

\section{Hypotheses of the Study}

1- There is no statistically significant relationship between the Jordanian society and the tourism profession from the point of view of tourism workers due to gender variable, age, number of years of service, social status, level of education, income.

2- There is no statistically significant relationship between the Jordanian society's view of the tourism profession from the point of view of tourism and social workers.

3- There is no statistically significant relationship between the Jordanian society's view of the tourism profession from the point of view of tourism workers and the personal

Stability of the tool:

* The stability of the instrument has been tested by the Cronbach Alpha test. In view of Table (1), the following is shown:

1 - The value of alpha for the paragraphs of the social sphere 0.74 .

2 - The value of alpha for the paragraphs of personal area 0.61 .

5 - The value of alpha for all paragraphs 0.67 .

All these values are greater than 0.60 there is stability in the study tool.

Table 1. Results of the Cronbach Alpha test for axes

\begin{tabular}{ll}
\hline Dimension & alpha value \\
\hline Social sphere & $\mathbf{0 . 6 4}$ \\
Personal domain & $\mathbf{0 . 6 8}$ \\
Total & $\mathbf{0 . 6 5}$ \\
\hline
\end{tabular}

Describe the personal and functional factors of respondents:

Table 2 presents a description of the personal and functional factors of the sample members working in tourism, as follows:

- Sex: $85.0 \%$ of the sample are male, $15.0 \%$ of whom are female.

- Age: $55.0 \%$ of the sample were between the ages of 26 and 36, 20\% were between 18 and 25 years old, $15.0 \%$ were between 37 and 47 years old and $20 \%$ were over the age of 48 years.

- Years of service: $35.0 \%$ of the respondents are between 6 and 9 years of age, $30 \%$ of whom serve between 2 and 5 years of service, $25 \%$ of their service years are 10 years and over, and $10 \%$ are years of service.

- Salary rate: $40.0 \%$ of the salary range between 551 and 650 dinars, $40.0 \%$ of salaries range between 651 and 1000 dinars, and $5.0 \%$ more than 1000 dinars and $15.0 \%$ salaries between 250 and 550 dinars.

- Social status: $55.0 \%$ of the sample were married, and $45.0 \%$ of the sample was unmarried.

- The level of education: $35.0 \%$ of the sample have bachelor's degrees, $30.0 \%$ of the diploma, $5.0 \%$ of the graduate campaign, $20.0 \%$ of the sample of the secondary, and $10.0 \%$ of the secondary. 
Table 2. Frequency and percentages of personality variables for respondents

\begin{tabular}{llll}
\hline Percentage (\%) & Frequency & Category & Variable \\
\hline 85.0 & 150 & Male & Gender \\
15.0 & 50 & Female & \\
20 & 50 & $25-18$ & \\
55 & 60 & $36-26$ & Age \\
15 & 40 & $47-37$ & \\
20 & 50 & +48 & Income \\
15 & 55 & $550-250$ & \\
40 & 60 & $650-551$ & \\
40 & 60 & $1000-651$ & \\
5 & 25 & +1001 & \\
10 & 20 & Less than secondary & \\
20 & 40 & High School & \\
30 & 60 & diploma & \\
35 & 65 & BA & \\
5 & 15 & Postgraduate & \\
10 & 30 & Years and less & \\
30 & 60 & $5-2$ & Years of work \\
35 & 70 & $9-6$ & \\
25 & 40 & $9+$ & \\
45 & 90 & Unmarried & \\
55 & 110 & Married & \\
\hline & & & \\
\end{tabular}

\subsection{Testing and Analysis of Hypotheses}

The first hypothesis:

There is no statistically significant relationship between the Jordanian society's view of the tourism industry from the point of view of tourism workers due to gender variable, age, number of years of service, social status, level of education, income.

First: Gender:

Table 3 data shows that there are no differences in the personal area due to the gender variable. Where the observed significance levels are greater than 0.05 .

As for the social field, the level of significance is less than 0.05 . That is, there are differences in this area due to the gender variable, and in favor of males.

Table 3. Gender variable results

\begin{tabular}{lllllll}
\hline \multirow{2}{*}{ Sig level for $t$ value } & \multirow{2}{*}{ T value for diff } & \multicolumn{2}{l}{ Sig level of } & \multicolumn{2}{c}{ Arith mean } & Dimension \\
\cline { 3 - 6 } & & $\mathrm{F}$ & $\mathrm{M}$ & $\mathrm{F}$ & $\mathrm{M}$ & \\
\hline 0.04 & 2.03 & 0.06 & 0.07 & 2.51 & 3.52 & Social sphere \\
0.06 & 1.25 & 002. & 000 & 2.36 & 3.16 & Personal domain \\
\hline
\end{tabular}

Second: Age:

Table 4 shows that:

- There are differences in the social field due to the variable age where the level of significance is less than 0.05 .

- The personal area, the level of significance of the viewer was greater than 0.05 , that is, there are no differences in the personal area due to the variable age.

Table 4. Results of a single test with respect to the age variable

\begin{tabular}{lll}
\hline Dimension & F test Sig & level for F test of diff \\
\hline Social sphere & 15.23 & 0.03 \\
Personal domain & 10.52 & 0.06 \\
\hline
\end{tabular}


Third: Number of years of service:

Table 5 shows that:

- There are differences in the personal field due to the variable years of service where the level of significance is less than 0.05 , which is any difference in the personal area due to the variable years of service.

- The level of significance of the social sector was greater than 0.05 , that is, there are no differences in the social field due to the variable years of service

Table 5. Results of the single contrast test in relation to the variable years of work

\begin{tabular}{lll}
\hline Dimension & F test Sig & level for F test of diff \\
\hline Social sphere & 7.10 & 0.07 \\
Personal domain & 3.56 & 0.02 \\
\hline
\end{tabular}

Fourth: Social Status:

Table 6 shows that there are differences in the personal area due to the variable of the social situation where the level of significance is less than 0.05 ,

The level of significance shown in the social sphere was greater than 0.05 , that is, there are no differences in the social field due to the variable social situation

Table 6. One sample test results for the social status variable

\begin{tabular}{lllllll}
\hline \multirow{2}{*}{ Sig level for $t$ value } & T value for diff & \multicolumn{2}{l}{ Sig level of } & \multicolumn{2}{l}{ Arith mean } & \\
\cline { 2 - 6 } & & F & M & F & M & Dimension \\
\hline 0.9 & 2.55 & 0.01 & 1.66 & 3.52 & 4.58 & Social sphere \\
0.3 & 2.44 & 0.02 & 2.65 & 3.69 & 4.26 & Personal domain \\
\hline
\end{tabular}

Fifth: The level of education:

Table 7 shows that:

- The level of significance of the social sector is less than 0.05 , that is, there are differences in this area due to the variable level of education.

- The level of significance of the personal sphere is greater than 0.05 , that is, there are no differences in this area due to the variable level of education

Table 7. Results of the single contrast test in relation to the education level variable

\begin{tabular}{lll}
\hline Dimension & F test Sig & level for F test of diff \\
\hline Social sphere & 6.89 & 0.01 \\
Personal domain & 7.21 & 0.08 \\
\hline
\end{tabular}

Sixth: Income:

Table 8 shows that:

- The level of significance of the personal domain is less than 0.05 , there are differences in this area due to the variable income,

- There are differences in the social field due to the income variable where the level of significance of the viewer was greater than 0.05 , which there are differences in this area due to the variable income.

Table (8): Results of the Single Contrast Test in relation to the income variable:

\begin{tabular}{lll}
\hline Dimension & F test Sig & level for F test of diff \\
\hline Social sphere & 7.54 & 0.09 \\
Personal domain & 8.47 & 0.04 \\
\hline
\end{tabular}


The third hypothesis:

There is no statistically significant relationship between the Jordanian society's view of the tourism profession from the point of view of tourism and social workers.

Table 9 shows that with the exception of paragraph 6, all the other paragraphs obtained less than 3.00. In other words, these things do not exist statistically, and this indicates that they do not represent social motives for Jordanian society to work in the tourism profession in Jordan.

As for the combined paragraphs, which represent the social dimension, the mean is 2.88 , which is less than 3.00. That is, the third hypothesis is accepted, that is, there is no statistically significant relationship between the Jordanian society's view of the tourism profession from the point of view of the workers in tourism and the social sphere.

Table 9. The arithmetic mean, the standard deviation, the $t$ value, and the significance level of the $t$ value of the monthly income

\begin{tabular}{|c|c|c|c|c|c|}
\hline Sig level & T-Value & Std. dev & $\begin{array}{l}\text { Arithmetic } \\
\text { Mean }\end{array}$ & Item & No. \\
\hline 0.12 & 2.56 & 0.30 & 3.56 & $\begin{array}{l}\text { The work in tourism allows the field to identify a } \\
\text { wide segment of society }\end{array}$ & 1 \\
\hline 0.02 & 1.25 & 0.50 & 2.22 & $\begin{array}{l}\text { Satisfaction of the Jordanian community in the } \\
\text { profession of tourism }\end{array}$ & 2 \\
\hline 0.03 & 6.25 & 0.60 & 2.36 & $\begin{array}{l}\text { Working in the tourism profession is easy and is } \\
\text { criticized by others }\end{array}$ & 3 \\
\hline 0.04 & 4.23 & 0.40 & 2.98 & $\begin{array}{l}\text { The rise of the work center in the tourism profession } \\
\text { in the eyes of Jordanian society }\end{array}$ & 4 \\
\hline 0.30 & 0.25 & 0.60 & 2.56 & $\begin{array}{l}\text { I am not embarrassed by the lack of understanding by } \\
\text { a society of the nature of the work that I do in the } \\
\text { tourism sector }\end{array}$ & 5 \\
\hline 0.01 & 6.05 & 0.36 & 3.96 & $\begin{array}{l}\text { The community looks positive direction of work in } \\
\text { tourism career }\end{array}$ & 6 \\
\hline 0.06 & 4.32 & 0.45 & 2.88 & All items & \\
\hline
\end{tabular}

The fifth hypothesis:

There is no statistically significant relationship between the Jordanian society's view of the tourism profession from the point of view of tourism and social workers.

Table 10 shows that with the exception of paragraph 7, the other paragraphs obtained a mean of less than 3.00 , and paragraph 7, although they obtained an arithmetic mean greater than 3.00 , the significance level is greater than 0.05 . In other words, all paragraphs of the personal domain are non-existent and non-existent.

The computational mean of the combined sentences was 2.54 , which is less than 3.00 , meaning that the fifth hypothesis is accepted. There is no statistically significant relationship between the Jordanian society's view of the tourism profession from the point of view of tourism and social workers.

Table 10. The arithmetic mean, the standard deviation, the value $t$, and the significance level of the value of $t$

\begin{tabular}{|c|c|c|c|c|c|}
\hline $\begin{array}{l}\text { Sig } \\
\text { level }\end{array}$ & T-Value & $\begin{array}{l}\text { Std. } \\
\text { dev }\end{array}$ & $\begin{array}{l}\text { Arithmetic } \\
\text { Mean }\end{array}$ & Item & No. \\
\hline 0.00 & 6.23 & 0.60 & 3.04 & I am proud to be working in the tourism sector & 1 \\
\hline 0.00 & 5.26 & 0.30 & 2.22 & My personal desire in this profession and feel it is suitable for me & 2 \\
\hline 0.00 & 0.25 & 0.50 & 1.65 & Working in the sector allows me to express my opinion freely and frankly & 3 \\
\hline 0.70 & 1.25 & 0.66 & 1.23 & $\begin{array}{l}\text { My career in the tourism profession develops my ability to solve the problems that } \\
\text { confront me and make appropriate decisions }\end{array}$ & 4 \\
\hline 0.80 & 0.36 & 0.36 & 2.69 & I feel that work in the tourism sector is achieving my ambition & 5 \\
\hline 0.60 & 3.65 & 0.54 & 2.54 & All items & \\
\hline
\end{tabular}




\section{Results}

The study found the following results

1- There is no statistically significant relationship between the Jordanian society's view of the tourism profession from the point of view of tourism and social workers.

2- The society's view of the work in the tourism sector is positive.

3. The Jordanian society's dissatisfaction with work in the tourism sector

4- The decline of the status of the tourism profession from the point of view of the Jordanian society.

5. There is no statistically significant relationship between the Jordanian society's view of the tourism profession from the point of view of tourism workers and the personal sphere.

6. The work in the tourism sector does not allow the expression of the employee's opinion freely and openly.

\section{Recommendations}

The study recommends as following:

1- The necessity of improving the Jordanian society's view of the tourism profession by introducing Jordanian citizens to the importance of the tourism sector.

2- Achieve the satisfaction of the community on this profession of tourism and try to integrate tourism institutions with community work.

3- Improve the elements of the personal sphere towards the promotion and development of tourism profession.

4- Tourism workers must feel confident and proud of his profession, and have a personal desire.

5- This profession allows him to express his opinion freely and frankly, and develop his ability to solve the problems facing him, and feel that work in tourism achieves his ambition.

\section{References}

Abu Hajar, A. (2011). Tourism Geography, Osama House for Publishing and Distribution. Amman, Jordan

Abu Rumman et al. (2013). Tourism Awareness and its Role in Enhancing the Competitiveness of Tourism and Travel Sector in Jordan: An Analytical Field Study.

Alsamaan, J. (2002). Difficulties Facing Female Employees in the Tourism Sector, Master Thesis. Unpublished, University of Jordan, Amman, Jordan

Bouderbala, R. (2016). Tourism Awareness and its Role in the Development of the Algerian Tourism Sector. Journal of Human Sciences, 3(2), 263-277.

Gharayba, K. (2012). Desert Tourism in the Arab World (Reality and Hope). Dar Kandil Publishing and Distribution, Jordan.

Khaled, et al. (2008). Local Communities' Awareness of the Role of the Jordanian Tourist Guide in Tourism Development. Jordanian Journal of Social Sciences, 1(1).

Kia, M., \& Abdel, M. (2002). Tourism Legislation and Principles, Amman. Dar Al Safa Publishing and Distribution.

Samawi, H. (1999). The reality of the career of tour guides in Jordan and evaluation of their performance. Studies Humanities and Social Sciences, 26(2), 564-545.

Samurai, S. et al. (2012). Availability of Technical and Scientific Skills in the Field of Tourism Workers: An Empirical Study of a Sample of Workers in the Tourism Sector in the Hashemite Kingdom of Jordan. Journal of Baghdad College of Economic Sciences, University, No. 30, Iraq.

Zubi, R. et al. (2015). Youth attitude towards women's work in the tourism sector: a case study of students at the University of Jordan. Jordanian Journal of Social Sciences, 8(1).

\section{Copyrights}

Copyright for this article is retained by the author(s), with first publication rights granted to the journal.

This is an open-access article distributed under the terms and conditions of the Creative Commons Attribution license (http://creativecommons.org/licenses/by/4.0/). 